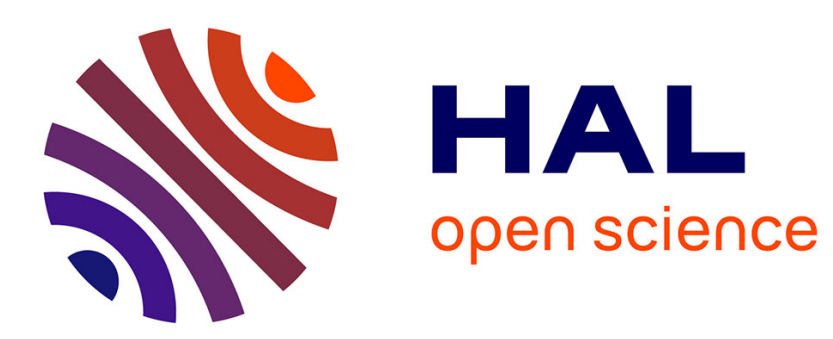

\title{
The effect of polydispersity on the crystallization of hard spherical colloids \\ P.N. Pusey
}

\section{To cite this version:}

P.N. Pusey. The effect of polydispersity on the crystallization of hard spherical colloids. Journal de Physique, 1987, 48 (5), pp.709-712. 10.1051/jphys:01987004805070900 . jpa-00210489

\section{HAL Id: jpa-00210489 https://hal.science/jpa-00210489}

Submitted on 1 Jan 1987

HAL is a multi-disciplinary open access archive for the deposit and dissemination of scientific research documents, whether they are published or not. The documents may come from teaching and research institutions in France or abroad, or from public or private research centers.
L'archive ouverte pluridisciplinaire HAL, est destinée au dépôt et à la diffusion de documents scientifiques de niveau recherche, publiés ou non, émanant des établissements d'enseignement et de recherche français ou étrangers, des laboratoires publics ou privés. 
Classification

Physics Abstracts

$05.20-64.70 \mathrm{D}-82.70$

\title{
THE EFFECT OF POLYDISPERSITY ON THE CRYSTALLIZATION OF HARD SPHER- ICAL COLLOIDS
}

\author{
P.N. Pusey \\ Royal Signals and Radar Establishment, St Andrews Road, \\ Malvern, WR14 3PS, U.K. \\ (Reçu le 29 janvier 1987, accepté le 5 mars 1987)
}

\begin{abstract}
Résumé.-Une dispersion de particules colloïdales sphériques ne peut cristalliser que si sa distribution de tailles (polydispersité) n'est pas trop large. On montre ici que les résultats de calculs et de simulations pour cet effet peuvent être simplifiés considérablement par l'emploi d'un indice universel de polydispersité. On présente également un modèle simple qui donne un résultat semblable. En général, la cristallisation d'une suspension colloïdale est empêchée lorsque la polydispersité (déviation standard de la distribution des tailles divisée par sa moyenne) dépasse une valeur critique située entre 6 et $12 \%$.
\end{abstract}

\begin{abstract}
To crystallize, spherical colloidal particles must not have too broad a spread of size (or polydispersity). Here it is pointed out that the findings of recent calculations and computer simulations concerning the effects of polydispersity on the crystallization of hard spherical particles are simplified considerably if cast in terms of a universal index of polydispersity. A simple model is shown to give a similar result. We find the crystallization of such a colloidal suspension is suppressed when the polydispersity, defined as the standard deviation of the particle size distribution divided by its mean, exceeds a critical value which lies in the range 6 to $12 \%$.
\end{abstract}

\section{Introduction}

There is considerable current interest in the phase behaviour of concentrated suspensions of spherical colloidal particles suspended in a liquid. As the concentration of such a suspension is increased a disorderorder transition, from a dense-fluid-like spatial arrangement of the particles to a crystalline arrangement, is frequently observed [1]. Concentrated colloidal suspensions are, of course, crucial components of many industrial processes ; they also constitute intringuing "models" for the behaviour of simple atomic and molecular systems. An important and generally unavoidable difference between molecules and colloidal particles is that, whereas the former are essentially ideally monodisperse (i.e. of identical size), in the latter case there is inevitably some distribution of particle size or polydispersity. Recently the effect of polydispersity on the disorder-order transition of "hard-sphere" colloids has been investigated, both by computer simulation $[2,3]$ and density functional theory [4]. It is found that, in suspensions with polydispersities exceeding a critical value, a stable crystalline phase is no longer able to form.

The purpose of this note is twofold. Firstly we point out that a considerable simplification is found when the results of the above-mentioned investigations are expressed in terms of a universal measure of polydispersity rather than in terms of parameters particular to the form of particle size distribution (PSD) chosen. Secondly a simple model is shown to give a similar prediction to the detailed calculations, thereby providing insight into the physical mechanism by which crystallization is suppressed. We find that, if the polydispersity $\sigma$ is defined as the ratio of the standard deviation to the mean of the PSD, its critical value lies in the range 0.06 to 0.12 .

\section{Previous work}

For their calculations based on density functional 
theory Barrat and Hansen [4] (henceforth $\mathrm{BH}$ ) used both triangular and rectangular PSDs ; in their computer simulations Dickinson and Parker [3] (henceforth DP) used the same triangular distribution. The latter is defined by

$$
P_{\mathrm{T}}(a)=\frac{1}{\left(\bar{a} \Delta_{\mathrm{T}}\right)^{2}}\left(\bar{a} \Delta_{\mathrm{T}}-|a-\bar{a}|\right) ;\left|\frac{a}{\bar{a}}-1\right|<\Delta_{\mathrm{T}} ;
$$

whereas the rectangular distribution is

$$
P_{\mathrm{R}}(a)=\frac{1}{2 \bar{a} \Delta_{\mathrm{R}}} ;\left|\frac{a}{\bar{a}}-1\right|<\Delta_{\mathrm{R}},
$$

where $a$ is the particle radius, $\bar{a}$ its mean and $\Delta_{T}$ and $\Delta_{R}$ are measures of the widths of the distributions. The parameter most conveniently used to characterize polydispersity is $\sigma$, defined by

$$
\sigma=\left(\overline{a^{2}}-\bar{a}^{2}\right)^{\frac{1}{2}} / \bar{a}
$$

where

$$
\overline{a^{n}}=\int \mathrm{d} a a^{n} P(a) .
$$

It is a trivial matter to calculate the polydispersities for the two distributions to give

$$
\sigma_{\mathrm{T}}=\Delta_{\mathrm{T}} / \sqrt{6}
$$

and

$$
\sigma_{\mathrm{R}}=\Delta_{\mathrm{R}} / \sqrt{3} .
$$

Barrat and Hansen found the critical polydispersities, above which crystallization was suppressed, to be $\Delta_{T} \approx 0.165$ and $\Delta_{R} \approx 0.110$; Dickinson and Parker found a critical value $\Delta_{T} \approx 0.28$. These results are listed in table I both in terms of $\Delta$ and of $\sigma$, calculated from equations (5) and (6), and will be discussed shortly.

\section{A simple model}

Another estimate of the critical degree of polydispersity can be obtained from the following simple argument. Consider a crystal having an average separation of the centres of nearest-neighbour particles equal to $L$. If (in a gedanken experiment) the polydispersity of the particles were increased, while the number concentration and mean size were kept constant, it seems reasonable that, due to distortion of the lattice, crystallization would be disrupted when a significant fraction of the particles achieved radii a greated than $L / 2$, half the nearest-neighbour separation. Then, for any (reasonably symmetrical) particle size distribution, crystallization requires

$$
\bar{a}(1+x \sigma)<L / 2,
$$

where $x$ is a number of order one which, for simplicity, we take to be equal to one

$$
\bar{a}(1+\sigma)<L / 2 .
$$

The structure of crystals of monodisperse hard spheres is close packed (face-centred cubic or hexagonal closepacked of a mixture of the two) having maximum volume-fraction $\phi \approx 0.74$ [5]. Thus, if $\rho$ is the number density of particles at volume fraction $\phi(\leq 0.74)$, we have [6]

$$
\begin{gathered}
\frac{4}{3} \pi\left(\frac{L}{2}\right)^{3} \rho,=0.74, \\
\frac{4}{3} \pi \bar{a}^{3} \rho=\phi,
\end{gathered}
$$

so that the nearest-neighbour separation $L$ for a crystal of volume fraction $\phi$ is related to the mean size $\bar{a}$ by

$$
\frac{L}{2}=\bar{a}\left(\frac{0.74}{\phi}\right)^{1 / 3} .
$$

Substitution of (10) into (8) gives, as the criterion for crystallization,

$$
\sigma<\left(\frac{0.74}{\phi}\right)^{1 / 3}-1
$$

For monodisperse hard spheres the most dilute crystal which can exist has $\phi \approx 0.545$ (the "melting" concentration) [7]. Thus, from (11), such a crystal requires $\sigma<0.11$ if it is to be disrupted by polydispersity. This value of the critical polydispersity is also listed in table I.

\section{Discussion}

We now discuss the results collected in table I, starting with the interesting finding that, when considered in terms of the global measure of polydispersity $\sigma$, BH's calculations predict almost exactly the same critical degree of polydispersity $\left(\sigma_{c} \approx 0.065\right)$ for both triangular and rectangular PSDs. An input into their density functional calculations is an expression for the direct correlation function $c_{a a^{\prime}}(r)$. In the Percus-Yevick approximation used by $\mathrm{BH} c(r)$ is given as a truncated polynomial in the interparticle separation $r$. As a consequence, calculations using this approximation lead to results expressed in terms of moments of the PSD. An important, though not widely appreciated, property of narrow relatively symmetrical distributions is that, whatever their detailed form, their normalized moments are given by a universal function of the standard deviation $\sigma[8,9]$ :

$$
\frac{\overline{a^{n}}}{\bar{a}^{n}}=1+\frac{n(n-1)}{2} \sigma^{2}+0\left(\sigma^{4}\right) .
$$


(The moments up to $n=3$ of the distributions (1) and (2) are given exactly by the first two terms of (12).)

Thus, in view of the small values of $\sigma(\leq 0.1)$ needed in BH's calculations, it is not surprising that their results are nearly independent of the detailed form chosen for the PSD.

Table I.- Estimates of the critical degree of polydispersity $\sigma_{\mathrm{c}}$

\begin{tabular}{|c|c|c|c|}
\hline Author & Distribution & $\Delta$ & $\sigma_{\mathrm{c}}$ \\
\hline $\mathrm{BH}[4]$ & Triangular & 0.165 & 0.067 \\
\hline $\mathrm{BH}[4]$ & Rectangular & 0.110 & 0.064 \\
\hline $\mathrm{DP}[3]$ & Triangular & 0.276 & 0.113 \\
\hline $\begin{array}{c}\text { Present work } \\
\text { (Eq. (11)) }\end{array}$ & $\begin{array}{c}\text { Any symmetrical } \\
\text { distribution }\end{array}$ & & 0.110 \\
\hline
\end{tabular}

The difference between the results of BH's calculation and DP's simulation of a similar system (see Table I) is probably due to a combination of approximations in the calculation and the fact that DP extrapolated results obtained on a small sample, 108 particles.

The simple model of section 3 was suggested by Lindemann's melting criterion : that a crystal melts when the thermally-induced root-mean-square displacement of an atom or particle reaches a characteristic fraction of the typical interparticle spacing [10]. In the present case the long-range order of the putative crystal is disrupted when the variability of particle size reaches a similar critical value $\sigma_{\mathrm{c}}$. Although, in both cases, the underlying principle is straightforward, theoretical determination of the actual value of the characteristic fraction is imprecise, requiring the assumption of a criterion such as that of equation (7). Thus the difference between the prediction of section 3 and BH's results (Table I) is probably not significant. It is interesting, in fact, that computer simulations [10] show crystals of monodisperse hard spheres to melt when the rms displacement of a particle reaches about $13 \%$ of the interparticle spacing $L$ or $6.5 \%$ of $L / 2$, a value very close to the $\sigma_{\mathrm{c}}$ found by $\mathrm{BH}$.

We now speculate briefly on the long-term fate of a concentrated particle suspension with polydispersity greater than the critical value. First we note that in the crystallization of nearly monodisperse spheres the fundamental motion appears to be diffusion of a particle over a distance comparable to its radius to find a site on the surface of a growing crystal [11]. It is the suppression by polydispersity of this relatively rappid crystallization which has been considered in this paper. It is possible that a podydisperse suspension having a monomodal PSD with $\sigma>\sigma_{\mathrm{c}}$ could show a fractionation or phase separation [4]. Then crystallites with different lattice parameters could form, each composed of particles taken from different sub-populations of the PSD having different mean sizes. The latter process would be much slower than the crystallization of an otherwise similar monodisperse suspension since it would require the transport of particles over distances comparable to the size of a crystallite. It also seems likely that suspensions with certain specific forms of broad but multimodal distribution could crystallize relatively easily. For example, in a suspension composed of two sharp fractions having a sufficiently large size difference, the smaller particles could fit into the interstices of a crystal made of the larger particles. Such "colloidal alloy" structures have been observed both in naturally-occurring opals [12] and synthetic colloids [13] which interact throught a (soft) shielded Coulombic potential.

Finally we mention that good model "nearly-hardsphere" colloidal particles exist $[1,14,15]$. These particles can be prepared with different degrees of polydispersity (admittedly in a somewhat uncontrolled fashion, at present). Indeed we have found that suspensions with a polydispersity up to about $6 \%$ crystallize $[1,15]$ whereas, in preliminary observations, a suspension with $\sigma$ greater than about $10 \%$ did not. Thus a reasonably accurate experimental determination of the critical value of $\sigma$, which, in view of the above discussions, is probably not very sensitive to the detailed form of the PSD, is not far off.

\section{Acknowledgments}

I thank Professor J.-P. Hansen for sending me a preprint of reference [4], Professor H.N.W. Lekkerkerker for a valuable discussion (as part of a programme funded by NATO Research Grant $n^{\circ} 132 / 84$ ) and a referee for several valuable suggestions.

\section{References}

[1] Pusey, P.N., Van Megen, W., Nature 320 (1986) 340.

[2] Dickinson, E.,Parker, R., Lal, M., Chem. Phys. Lett. 79 (1981) 578.

[3] Dickinson, E., Parker, R., J. Physique Lett. 46 (1985) L-229.

[4] BARrat, J.L., HANSEN, J.P., J. Physique 47 (1986) 1547.

[5] Colot, J.L., Baus, M., Molec. Phys. 56 (1985) 807. 
[6] Strictly $\phi=\frac{4}{3} \pi \overline{a^{3}} \rho$. However for narrow distributions $\overline{a^{3}}=\bar{a}^{3}\left(1+3 \sigma^{2}\right)$ (Eq. (12)) so that to first order in $\sigma$, the level of approximation used here, $\overline{a^{3}}=\bar{a}^{3}$.

[7] Hoover, W.G., ReE, F.H., J. Chem. Phys. 49 (1968) 3609 .

[8] Parry, G., Pusey, P.N., J. Opt. Soc. Am. 69 (1979) 796.

[9] Pusey, P.N., Fijnaut, H.M., Vrij, A., J. Chem. Phys. 77 (1982) 4270.

[10] HAANSEN, J.P., McDonald, I.R., Theory of Simple Liquids (Academic Press, London) 1976, p. 361.
[11] Aastuen, D.J.W., Clark, N.A., Cotter, L.K., ACKerson, B.J., Phys. Rev. Lett. 57 (1986) 1733.

[12] Sanders, J.V., Philos. Mag. A42 (1980) 705.

[13] HaChISU, S., YoshimUra, S., Nature 283 (1980) 188.

[14] VRIJ, A., Jansen, J.W., Dhont, J.K.G., PathmaMANOHARAN, C., KOPS-WERKHOVEN, M.M., FIJNAUT, H.M., Faraday Discuss. Chem. Soc. 76 (1983) 19.

[15] VAN Megen, W., OTTEWILl, R.H., OWens, S.M., PUSEY, P.N., J. Chem. Phys. 82 (1985) 508. 